\title{
Özofagus skuamoz hücreli papillomatosis: Bir olgu sunumu ve literatürün gözden geçirilmesi
}

\author{
Esophageal squamous cell papillomatosis: A case report and review of literature
}

Mustafa YAKUT, Kubilay ÇINAR, Ramazan IDILMAN, Kadir BAHAR

Ankara Tıp Fakültesi, Gastroenteroloji Bilim Dalı, Ankara

Özofagusun benign bir lezyonu olan skuamoz hücreli papillomanın etyolojisi net değilse de gastroözofageal reflü hastalığına bağlı özofajit veya Barret lezyonuna bağlı kronik irritasyon ve human papilloma virus infeksiyonu ile ilișkilendirilmiștir. Özofagus skuamoz hücreli papilloması sıklıkla soliter ve distal yerleşimlidir. Bu olgumuzda tüm özofagusu tutan çok sayıda skuamoz hücreli papillomalar vardi.

Anahtar Kelimeler: Skuamoz hücreli papillom, özofagus, HPV

\section{GİRIŞ}

Özofagus skuamoz hücreli papilloması nadir görülen, benign, skuamoz epitelyal bir tümördür. Genellikle endoskopik incelemede rastlantısal olarak görülür $(1,2)$. Özofagus skuamoz hücreli papilloma sıklığı otopsi ve endoskopi serilerinde $\% 0.01 \% 0.45$ oranlarında bildirilmiştir (3-6).

Özofagus skuamoz hücreli papillomanın etyolojisinde 2 faktörün rol aldığı düşünülmektedir. Birincisi minor travma, alkol, tütün, kronik besin "impaction", gastroözofageal cerrahi öyküsü ve gastroözofageal reflü hastalığı (GERD) gibi nedenler ile kimyasal veya mekanik irritasyona cevap olarak mukozada hiper-rejeneratif yanıt oluşmasıdır. Özofagus skuamoz hücreli papillomanın alt özofagusta daha sık olması, bu bölgenin GERD'den sik etkilenmesi nedeniyle mukozal irritasyon teorisini desteklemektedir (4).

Diğer teori ise human papilloma virus (HPV) infeksiyonunun etyolojide rol aldığı yolundadır. Syrjanen ve arkadaşları HPV'nin etyolojide rol aldığını göstermişlerdir. Ancak HPV'nin etyolojideki rolü hala tartışmalıdır (5).

\section{OLGU SUNUMU}

Kırk sekiz yaşında kadın hasta kliniğimize yutma güçlüğü şikayeti ile başvurdu. Şikayeti son bir kaç aydır artış göstermişti. Hastanın kilo kaybı, bulantı, kusma şikayetleri mevcut değildi. Sigara ve alkol kullanmiyordu. Hikayesinde radyoterapi öyküsü veya yakın akrabalara ait malign hastalık öyküsü yoktu.

Fizik muayenede baş-boyun ve gastrointestinal sistem normaldi. Laboratuvar incelemesinde Hgb: $12.1 \mathrm{gr} / \mathrm{dL}, \mathrm{WBC}$ :
The pathogenesis of esophageal squamous papilloma is not fully open, but it is associated with esophagitis due to gastroesophageal reflux disease or Barrett's lesions and HPV infection. Esophageal squamous cell papillomas are usually located solitary and the distal esophagus. In this case multiple squamous cell papillomas of the esophagus is reported.

Key words: Esophagus, squamous cell papilloma, HPV

7200/ $\mathrm{mm}^{3}$, trombosit: $267.000 / \mathrm{mm}^{3}$ olup sinırda anemi d1şında tam kan değerleri normal sınırlarda idi. Hastanın biyokimyasal incelemesinde transaminazlar, ALP, GGT, kreatinin ve albumin değerleri normal sinırlarda idi.

Hastanın tüm batın ultrasonografisinde patolojik bulgu saptanmadı. Gastroskopisinde özofagus proksimalinden başlayarak özofagogastrik bileşkeye kadar tüm özofagusu diffüz olarak tutan 0.5-1 cm boyutları arasında değişen, beyaz renkte, çok sayıda parmaksı çıkıntı şeklinde polipoid lezyonlar izlendi (Şekil 1, 2). Çok sayıda lezyondan biyopsiler alındı. Hastanın değişik lezyonlarından alınan tüm biyopsi örnekleri skuamoz hücreli papilloma ile uyumlu idi.

\section{TARTIŞMA}

Gastroözofageal reflü, reflu özofajit ve hiatal herni gibi özofagus skuamoz hücreli papilloma etyolojisinde rol oynadığı düşünülen hastalıkların coğrafik dağılımı hastalığın prevelansı ve yerleşim yeri ile ilişkili olabilir. İtalya ve Japonya'da yapılan çalışmalarda reflü özofajit sıklığının batı ülkelerine oranla daha düşük olması nedeni ile bu bölgelerde özofagus skuamoz hücreli papillomanın daha çok orta özofagusa yerleşim gösterdiği ve kadın dominansı olduğu bildirilmiştir $(5,7,8)$. Ayrıca özofagus skuamoz hücreli papillomanın kalıtsal hastalik olan "Angioma serpiginosum vascular streaks" ile birlikteliği de bildirilmiştir (9).

Papillomalar iyi sınırlı, düz yüzeyli nodüler veya polip şeklinde lezyonlardır. Sıklıkla 2 cm'den küçük olup tipik olarak ül- 

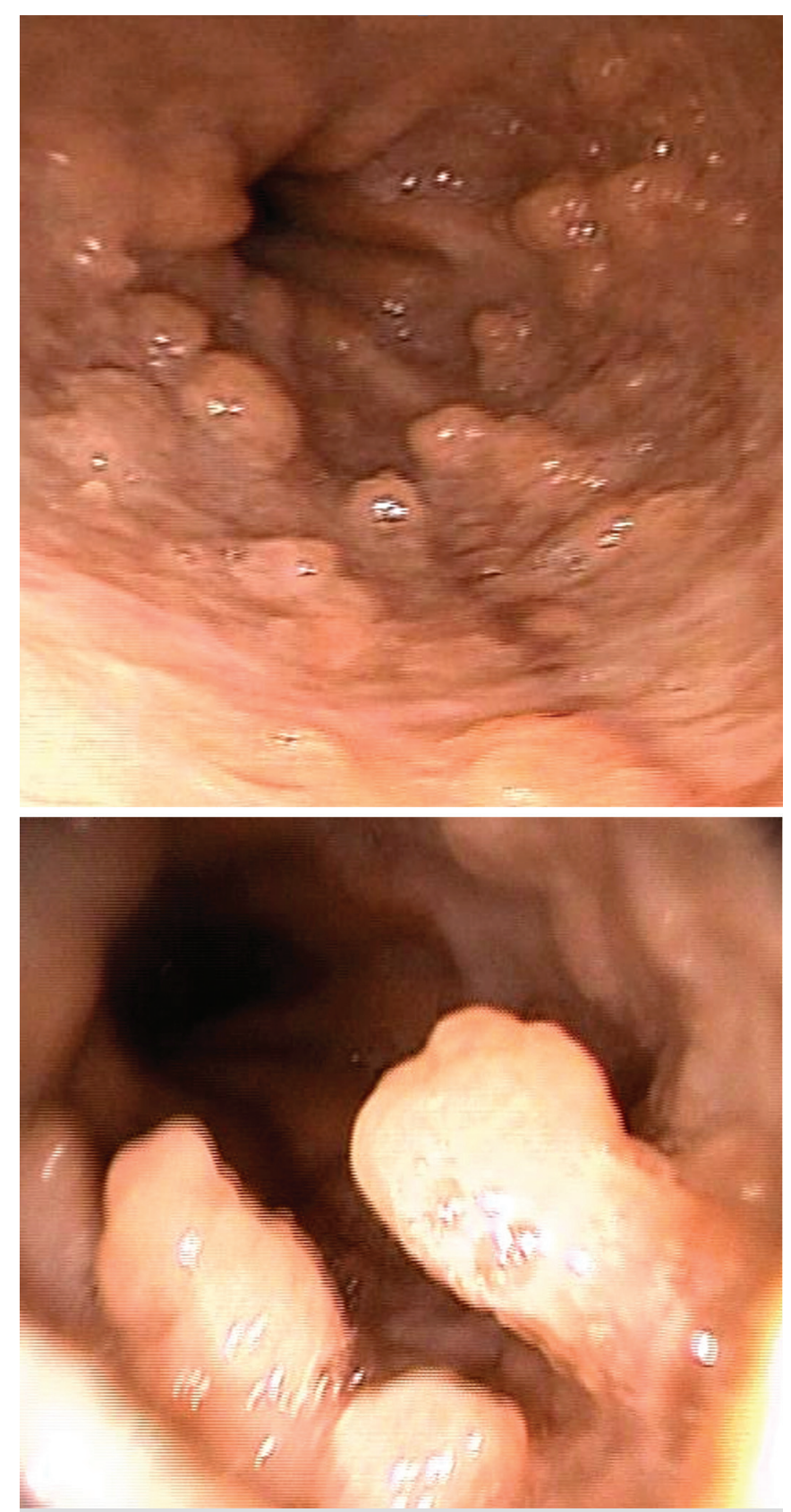

Şekil 1, 2. Özofagusta proksimalden başlayarak özofagogastrik bileşkeye kadar tüm özofagusu diffuz olarak tutan $0.5-1 \mathrm{~cm}$ boyutları arasında değişen çok sayıda parmaksı çıkıntı şeklinde polipoid lezyonlar.

ser ve nekroz izlenmez. Poliplerin ortalama boyları 4-5 mm $\operatorname{dir}(10)$.

Genellikle endoskopide küçük, beyaz ya da pembe polipoid lezyonlar şeklinde görülür ve çoğu özofagusun $1 / 3$ distalinde lokalize ve tektir (4, 11-13). Çoğu insidental, tek lezyon, distal özofagusa lokalize olup GERD ve kronik özofageal irritasyona eşlik eder (14). Multiple papilloma kümeleri (Clusters of multiple papillomas - papillomatosis) nadir görülür ve proksimal özofagusta görüldüğünde sıklıkla HPV eşlik eder (15, 16). Özofagus skuamoz hücreli papilloma daha az siklıkta multipl polipoid lezyonlar şeklinde de bildirilmiştir (17). Ay- rıca özofagus papilloma büyük kitle lezyonu şeklinde de bildirilmiştir (5, 18). Ağır sigara ve alkol kullanımı sıklıkla eşlik eder $(19,20)$.

Önceden yayınlanan çalışmaların çoğunda hastalar orta yaşlı, erkek dominansı (batı) ve çoğu alt özofagusta lokalize olarak bildirilmiş. Ancak Japonya'dan yapılan bir çalışmada erkek/kadın oranı 1/1.57 ve orta özofagus tutulumu daha sık (52.6\%) olarak rapor edilmiştir (4).

Özofagus papillomalarının çoğu endoskopik inceleme sırasında insidental olarak saptanır. Bildirilen olgularda en sık semptom dispepsi ve retrosternal yanmadir. Papilloma yaygınlığı ve boyutuna göre disfaji görülebilir. Çok nadir olarak belirgin kilo kaybı ve mekanik dilatasyon ihtiyacı bildirilmiştir (20-24).

Özofagus skuamoz hücreli papillomanın histopatolojik değerlendirilmesinde üzeri hiperplastik squamoz epitelle örtülü papiller görüntü ile karakterizedir. Bazı olgularda epitelde nötrofil infiltrasyonu (hafif, orta, ileri) ve koilositoz görülebilir. Özofagus skuamoz hücreli papillomanın proliferatif aktivitesi nonneoplastik skuamoz epitele göre daha yüksektir (4).

Özofagus kanseri, sigara, alkol, fungal toksin, nutrisyonel eksiklikler ve sıcak yiyecek-içecekler ile ilişkilidir. HPV serviks kanseri major nedeni olmasına rağmen Syrjänen ve ark. 2002 de yaptığı metaanalizde özofagus skuamoz hücreli kanserde \%15.2 oranında HPV DNA pozitifliği bildirmişlerdir (21).

Özofagus skuamoz hücreli papillomanın premalign potansiyeli literatürde tartışlan bir konudur (19). Larenx ve kadın genital trakt için papillamotosis prekanseroz olarak kabul edilir. Özofagusta papillomatosis ile ilişkili üst ve orta özofagus karsinomları tanımlanmış ise de papillomatosis ve özofagus Ca arasındaki ilişki azdır. Yüksek insidans bölgelerinde özofagus Ca'da HPV sıklığı \%17'lere kadar bildirilmiştir (25). Özogagus skuamoz hücreli papillomada HPV prevelansı \%0 \%64 oranlarında bildirilmiştir (4). Özofagus skuamoz hücreli papilloma benign bir lezyondur, uzun süreli takiplerde malignitenin eşlik etmediği bildirilmiştir. Nadiren de skuamoz hücreli Ca ile komplike olabilir (26-29).

HPV insanlarda enfeksiyona neden olan bir virüstür ve 100 civarında türü vardır. Daha çok genitoüriner trakt, cilt, üst solunum yolunu ve daha az sıklıkta özofagusu tutabilir. Özofagus skuamoz hücreli Ca’nın HPV ile ilişkili olabileceği bildirilmiştir $(29,30)$.

Özofagus mukozasının lugol ile boyanması yöntemi endoskopik olarak görünmeyen karsinom ve displaziyi saptamak için kullanılır (31). HPV DNA'yı saptamada PCR daha sensitiftir. HPV genotip 6 ve 11 major subtiptir. HPV pozitif skuamoz hücreli papilloma hastaları daha genç, kadın baskın, orta özofagus kaynaklıdır $(4,14)$. 
Klinik seyir değişken olup spontan regresyondan skuamoz hücreli kanser gelişmine kadar değişebilir $(19,21)$. Özofagus skuamoz hücreli papilloma olguları benign seyirli olup bazen spontan regresyon olabilir. Bazı olgularda endoskopik takip yapılmış ve malignite gelişmediği bildirilmiştir. Özofagus skuamoz hücreli papillomada çeşitli tedavi yöntemleri kullanılmıştır. Endoskopik elektrokoagülasyon ve cerrahi eksizyon da denenmiştir. Fotodinamik tedavi (PDT), Barrett özofagus ve yüzeyel adeno Ca'da başarıyla kullanılmıştır. Ancak özofagus skuamoz hücreli papillomada kullanımı net değildir. Bir olguda (özofagus skuamoz hücreli papilloma + high grade displazi) HALO90 Ablasyon sistemi ile radyo frekans tedavisi ile birinci seanstan sonra semptomlar rahatlamış ancak 4 seans sonrası skuamoz cell kanser gelişimi nedeni ile işleme ara verilmiş. Bir olguda da PDT ve özofagus stentlemesi yapılmış semptomların rahatladığı bildirilmiştir (18-21).

Bizim olgumuzda diffüz olarak çok sayıda lezyon mevcuttu ve literatürde daha çok insidental olarak saptanan lezyonların aksine disfajisi vardı. Bu kadın hastamızda gastroözofageal reflü hastalığı, alkol ve sigara kullanımı yoktu. Patolojik olarak çok sayıdan alınan lezyondan skuamoz hücreli papilloma tanısı doğrulandı. Dokuda HPV çalışamadığımızdan olası etyoloji olarak HPV infeksiyonu dışlanamamıştır.

\section{KAYNAKLAR}

1. Narayani RI, Young GS. Recurrent proximal esophageal stricture associated with dysplasia in squamous cell papillomatosis. Gastrointest Endosc 2002; 56: 591-4.

2. Adler RH, Carberry DM, Ross CA. Papilloma of the esophagus: association with hiatal hernia. J Thorac Surg 1959; 37: 625-35.

3. Lombardi JP, Tang D, Myhre OA. Squamous cell papilloma of the esophagus: a case report and review of the literature. Int Surg 1980; 65: 45961

4. Takeshita K, Murata S, Mitsufuji S, et al. Clinicopathological characteristics of esophageal squamous papillomas in Japanese patients-with comparison of findings from Western countries. Acta Histochem Cytochem 2006; 39: 23-30.

5. Mosca S, Manes G, Monaco R, et al. Squamous papilloma of the esophagus: long-term follow up. J Gastroenterol Hepatol 2001; 16: 857-61.

6. Yoo SS, Lee WH, Ha J, et al. The prevalence of esophageal disorders in the subjects examined for health screening. Korean J Gastroenterol 2007; 50: 306-12.

7. Kuniko Takeshita, Shin-ichiMurata, Shoji Mitsufuji, Naoki Wakabayashi, etal. Clinicopathological Characteristics of Esophageal Squamous Papillomas in Japanese Patients—With Comparison of Findings from Western Countries. Acta Histochem Cytochem. 2006 2; 39(1): 23-30.

8. Sablich R, Benedetti G, Bignucolo S, Serraino D. Squamous cell papilloma of the esophagus. Report on 35 endoscopic cases. Endoscopy 1988; 20: 5-7.

9. Talamini G, Capelli P, Zamboni G, et al. Alcohol, smoking and papilloma virus infections as risk factors for esophageal squamous-cell papilloma and esophageal squamous-cell carcinoma in Italy. Int J Cancer 2000; 86: 874-8.

10. Blinkenberg EO, Brendehaug A, Sandvik AK, et al. Angioma serpiginosum with oesophageal papillomatosis is an X-linked dominant condition that maps to Xp11.3-Xq12. Eur J Hum Genet 2007; 15: 543-7.

11. Lavergne D, DeVilliers EM. Papillomavirus in esophagea 1 papillomas and carcinomas. Int J Cancer 1999;80:680-4.

12. Narayani RI, Young GS. Recurrent proximal esophageal stricture associated with dysplasia in squamous cell papillomatosis. Gastrointest Endosc 2002; 56: 591-4.

13. Ferrari AP, Lanzoni VP, Kondo M. Esophageal squamous cell papilloma. Report of 3 cases. Diagnostic aspects. Rev Assoc Med Bras 1995; 41: 266-70.

14. Carr NJ, Monihan JM, Sobin LH. Squamous cell papilloma of the esophagus: a clinicopathologic and follow-up study of 25 cases. Am J Gastroenterol 1994; 89: 245-8.

15. Politoske EJ. Squamous papilloma of the esophagus associated with the human papillomavirus. Gastroenterology 1992; 102: 668-73.

16. Sandvik AK, Aase S, Kveberg KH, et al. Papillomatosis of the esophagus. J Clin Gastroenterol 1996; 22: 35-7.

17. Szanto I, Szentirmay Z, Banai J, et al. Squamous papilloma of the esophagus. Clinical and pathological observations based on 172 papillomas in 155 patients. Orv Hetil 2005; 146: 547-52.

18. Quitadamo M, Benson J. Squamouspapilloma of theesophagus: a casereportandreview of theliterature. Am J Gastroenterology 1988; 83: 194201.

19. Inomata S, Aoyagi K, Eguchi K, Sakisaka S. Giant esophageal papilloma. Gastrointest Endosc 2004; 60: 430.

20. Kibria R, Arkam S, Moezzi J, Ali S. Esophageal squamous papillomatosis with dysplasia. Is there a role of balloon-based radiofrequency ablation therapy? Acta Gastroenterol Belg 2009; 72: 373-6.

21. Janson JA, Baillie J, Pollock M. Endoscopic removal of esophageal condylomata acuminatum containing human papilloma virus. Gastrointest Endosc 1991; 37: 367-70.

22. Dumot JA, Vargo JJ, Zuccaro G Jr. Esophageal squamous papilloma causing dysphagia. Gastrointest Endosc 2000; 52: 660.

23. Al-Sohaibani MO, Al-Rashed RS. Squamous papilloma of the esophagus - a clinicopathologic study of 10 cases and review of the literature. Ann Saudi Med 1995; 15: 140-2.

24. John A. Dumot, DO John J. Vargo, MD , GregZuccaro, Jr., MD. ESOPHAGEAL SQUAMOUS PAPILLOMA CAUSING DYSPHAGIA. GASTROINTESTINAL ENDOSCOPY 2000;52(5);p.660

25. Syrjänen KJ. HPV infections and esophageal cancer. J Clin Pathol 2002; 55: 721-8.

26. Waluga M, Hartleb M, Sliwinski ZK, et al. Esophageal squamous-cell papillomatosis complicated by carcinoma. Am J Gastroenterol 2000; 95: 1592-3.

27. Van Cutsem E, Geboes K, Visser L, Devos R, JanssensJ,Lerut T, et al. Squamous papillomatosis of the esophagus with malignant degeneration and demonstration of the human papilloma virus. Eur J Gastroenterol Hepatol 1991;3:561-6

28. Wolfsen HC, Hemminger LL, Geiger XJ, et al. Photodynamic therapy and endoscopic metal stent placement for esophageal papillomatosis associated with squamous cell carcinoma. Dis Esophagus 2004; 17: 18790.

29. Reed PA, Limauro DL, Brodmerkel GJ Jr, Agrawal RM. Esophageal squamous papilloma associated with adenocarcinoma. Gastrointest Endosc 1995; 41: 249-51 
30. Atilla T, Fu A, Gopinath N, et al. Esophageal papillomatosis complicated by squamous cell carcinoma. Can J Gastroenterol 2009; 23: 415-9.

31. Yao PF, Li GC, Li J, et al. Evidence of human papilloma virus infection and its epidemiology in esophageal squamous cell carcinoma. World J Gastroenterol 2006; 12: 1352-5.

32. Ravakhah K, Midamba F, West C. Esophageal papillomatosis from human papilloma virus proven by polymerase chain reaction. Am J Med Sci 1998; 316: 285-8
33. Dawsey SM, Fleischer DE, Wang GQ, et al. Mucosal iodine staining improves endoscopic visualization of squamous dysplasia and squamous cell carcinoma of the esophagus in Linxian, China. Cancer 1998; 83: 220-31 